\title{
How Absorbed Hydrogen Affects Catalytic Activity of Transition Metals**
}

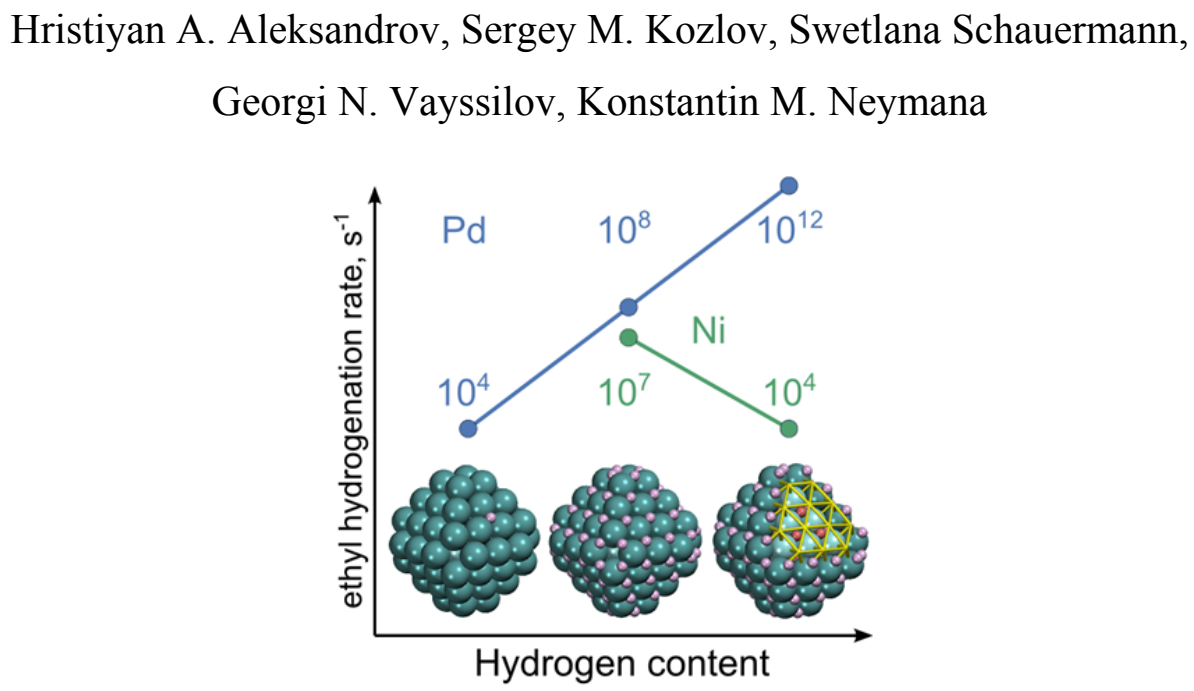

\section{Table of Content graph}

Subsurface hydrogen, $\mathrm{H}^{\text {sub }}$, is shown to either increase or decrease significantly the bond energy and the reactivity of the adsorbed hydrogen, $\mathrm{H}^{a d}$, depending on the metal. We calculate a representative reaction, ethyl hydrogenation, to speed up on $\mathrm{Pd}$ and $\mathrm{Pt}$, but to slow down on $\mathrm{Ni}$ and $\mathrm{Rh}$ in the presence of $\mathrm{H}^{\text {sub }}$, especially on metal nanoparticles. The reasons are i) occupation of antibonding $\mathrm{H}-\mathrm{Pd}$ and $\mathrm{H}-\mathrm{Pt}$ states and ii) electrostatic strengthening of polar $\mathrm{H}$ $\mathrm{Ni}$ and $\mathrm{H}-\mathrm{Rh}$ bonds by $\mathrm{H}^{\text {sub }}$.

${ }^{[a]}$ Dr. Hristiyan A. Aleksandrov, Sergey M. Kozlov, Prof. Dr. Konstantin M. Neyman

Departament de Química Física and Institut de Química Teòrica i Computacional (IQTCUB), Universitat de Barcelona, Martí i Franquès 1, 08028 Barcelona, Spain

Dr. Hristiyan A. Aleksandrov, Prof. Dr. Georgi N. Vayssilov

Faculty of Chemistry and Pharmacy, University of Sofia, 1126 Sofia, Bulgaria

Dr. Swetlana Schauermann

Department of Chemical Physics, Fritz-Haber-Institut der Max-Planck-Gesellschaft, 14195 Berlin, Germany

Prof. Dr. Konstantin M. Neyman

Institució Catalana de Recerca i Estudis Avançats (ICREA), 08010 Barcelona, Spain

Phone +349340 37 212, Fax +34934021231

E-mail: konstantin.neyman@icrea.cat

http://www.icrea.cat/Web/ScientificForm.aspx?key=292

${ }^{\left[{ }^{* *}\right]}$ The authors thank Prof. H.-J. Freund, Dr. S. Shaikhutdinov and Dr. L. V. Moskaleva for valuable discussions and critical reading of the manuscript. We acknowledge financial support provided by the EU (FP7NMP.2012.1.1-1, project ref. $\mathrm{N}^{\circ}$ 310191), the Spanish MINECO (grant CTQ2012-34969), MEDU (grants SB2010-0172 for H.A.A. and AP2009-3379 for S.M.K.) and Generalitat de Catalunya (grants 2014SGR97 and XRQTC). H.A.A. and G.N.V. are grateful to the Bulgarian Science Fund (grant DCVP 02/1) and the FP7 programme (project Beyond Everest). S.S. thanks the Verband der Chemischen Industrie for a Dozentenstipendium. We gratefully acknowledge the computer resources provided by the Red Española de Supercomputación.

Supporting information for this article is available on the WWW http://dx.doi.org/10.1002/anie.201405738R2 
Heterogeneous catalysis is commonly governed by surface active sites. Yet, areas just below the surface can also influence catalytic activity, for instance, when fragmentation products of catalytic feeds penetrate inside catalysts. In particular, $\mathrm{H}$ absorbed below the surface is required for certain hydrogenation reactions on metals. Herein, we show that sufficient concentration of subsurface hydrogen, $\mathrm{H}^{\text {sub }}$, may either increase or decrease significantly the bond energy and the reactivity of the adsorbed hydrogen, $\mathrm{H}^{a d}$, depending on the metal. We predict a representative reaction, ethyl hydrogenation, to speed up on $\mathrm{Pd}$ and $\mathrm{Pt}$, but to slow down on $\mathrm{Ni}$ and $\mathrm{Rh}$ in the presence of $\mathrm{H}^{\text {sub }}$, especially on metal nanoparticles. The identified effects of subsurface $\mathrm{H}$ on surface reactivity are indispensable for atomistic understanding of hydrogenation processes on transition metals and interactions of hydrogen with metals in general.

For a long time scientists have been studying interaction of hydrogen with transition metals, in particular with Pd. The latter is highly permeable for $\mathrm{H}$ and widely used as a hydrogenation catalyst. ${ }^{[1,2]}$ Despite strong research efforts, it is still controversially discussed in which way $\mathrm{H}^{\mathrm{sub}}$ atoms absorbed just beneath the top metal layer affect surface reactions. For instance, it is uncertain whether $\mathrm{H}^{\text {sub }}$ species directly participate in hydrogenation of alkyls on $\mathrm{Pd}$, as also discussed for $\mathrm{Ni}$ catalysts. ${ }^{[3,4]}$ As a touchstone reaction we have chosen alkyl to alkane hydrogenation step, which on Pd catalysts is known to be critically affected by the $\mathrm{H}^{\text {sub }}$ content. $^{[5-7]}$ (See also our experimental data in Supporting Information (SI) and in Figure S1.) Importantly, hydrogenation activity of Pd is qualitatively different on single-crystal and nanoparticle (NP) samples. ${ }^{[} 6^{]}$Thus, to account for a part of the complexity of the subsurface chemistry ${ }^{[8]}$ and involvement of $\mathrm{H}^{\text {sub }}$ in the hydrogenation on metal catalysts we go beyond the consideration of only single-crystal surfaces and explore NP models as well. After an indepth analysis of the processes on Pd we critically compare it with three other transition metals, Pt, Ni and Rh, whose bulk or NP forms were experimentally shown to absorb $\left.\mathrm{H}{ }^{[} 4,9\right]$

Our density-functional calculations of Pd catalysts are performed for $\mathrm{Pd}(111)$ extended (slab) and unsupported $\mathrm{Pd}_{79}$ NP models with different arrangements and concentrations of $\mathrm{H}$ atoms (Figure 1a). Note that bare Pd NPs of a similar size sufficiently accurately mimic the NPs deposited on inert metal-oxides. ${ }^{[10]}$ We consider the reactivity of terrace sites on $\{111\}$ facets of the $\mathrm{Pd}_{79} \mathrm{NP}$, which is representative for larger Pd NPs commonly employed in catalytic experiments. ${ }^{[11]}$ Edge sites are not discussed here since we did not find them to be more active than the terrace sites in the reaction under scrutiny. Theoretical studies reveal that $\mathrm{H}^{\text {sub }}$ is bound weaker than $\mathrm{H}^{a d}$ on $\mathrm{Pd}^{[12]}$ and other transition metals, ${ }^{[13]}$ implying that at equilibrium conditions $\mathrm{H}$ occupies subsurface positions only after filling most of the surface positions. ${ }^{\left[{ }^{12,14]}\right.}$ In some papers the effect of the $\mathrm{H}^{\text {ad }}$ atoms on the $\mathrm{H}^{\text {sub }}$ was considered for 
transition metal slabs, ${ }^{[15]}$ while the influence of $\mathrm{H}^{\text {sub }}$ on $\mathrm{H}^{\text {ad }}$ reactivity analyzed in the present paper was not explored in due detail. Thus, for both $\operatorname{Pd}_{79} \mathrm{NP}$ and $\operatorname{Pd}(111)$ slab different hydrogen contents were represented via three types of models: (i) low-coverage models with just one adsorbed $\mathrm{H}^{a d}$ atom, $\mathrm{H}^{a d}{ }_{1} \mathrm{H}^{\text {sub }}{ }_{0} / \mathrm{Pd}(\mathrm{NP})$ and $\mathrm{H}^{\text {ad }}{ }_{1} \mathrm{H}^{\text {sub }}{ }_{0} / \mathrm{Pd}(111)$; (ii) surface-saturated ${ }^{[16]}$ models, $\mathrm{H}^{a d}{ }_{78} \mathrm{H}^{\text {sub }}{ }_{0} / \mathrm{Pd}(\mathrm{NP})$ and $\mathrm{H}^{a d}{ }_{7} \mathrm{H}^{\text {sub }}{ }_{0} / \mathrm{Pd}(111)$; and (iii) subsurface-saturated models, $\mathrm{H}^{a d}{ }_{78} \mathrm{H}^{\text {sub }}{ }_{24} / \mathrm{Pd}(\mathrm{NP})$ and $\mathrm{H}^{a d}{ }_{7} \mathrm{H}^{\text {sub }} / \mathrm{Pd}(111)$. High exposure of $\mathrm{Pd}$ to $\mathrm{H}_{2}$ under experimental hydrogenation conditions ${ }^{[}$Fehler! Textmarke nicht definiert. $5^{5}$ corresponds to the regimes (ii) or (iii). We study ethyl hydrogennation to ethane, $\mathrm{C}_{2} \mathrm{H}_{5}+\mathrm{H} \rightarrow \mathrm{C}_{2} \mathrm{H}_{6}$, (Figure S6) as a representative surface reaction because alkyl hydrogenation on $\mathrm{Pd}$ was observed to be particularly sensitive to the presence of $\mathrm{H}^{\text {sub }}$ (see SI and Figure S1); our benchmark calculations of butyl hydrogenation on Pd NPs revealed very similar trends in the reactivity (see Table 1). Note, however, that for the examined reaction the surface concentration of the alkyl intermediate hardly depends on the concentration of the $\mathrm{H}^{\text {sub }}$ species (see $\mathrm{SI}$ ).

The hydrogenation of ethyl is exothermic by $50-140 \mathrm{~kJ} \mathrm{~mol}^{-1}$ (Table 1) for all catalyst models addressed, implying that only kinetic aspects need to be investigated in depth. We first examined possible reaction paths of ethyl recombination directly with $\mathrm{H}^{\text {sub }}$ atom (see Figure S2). However, the attacking $\mathrm{H}^{\text {sub }}$ emerging from the subsurface area of Pd was inevitably stabilized on the surface and converted to $\mathrm{H}^{\text {ad }}$, which subsequently acted as a reactant, similarly to methyl hydrogenation on $\mathrm{Ni}(111) \cdot{ }^{[}, 4^{]}$Therefore, in the following only the attack of alkyl species by a surface $\mathrm{H}^{\text {ad }}$ atom is discussed.

Results in Figure 1 predict that increasing the hydrogen content should accelerate the reaction on Pd NPs as well as on the Pd(111) single-crystal surface. As one moves from the bare NP with just one $\mathrm{H}^{a d}$ to the surface-saturated NP, the Gibbs activation energy of hydrogenation decreases by $19 \mathrm{~kJ} \mathrm{~mol}^{-1}$ (Table 1). This corresponds to a three orders of magnitude higher hydrogenation rate at $298 \mathrm{~K}$. The activation barriers for the low-coverage and surface-saturated single-crystal models agree within $2 \mathrm{~kJ} \mathrm{~mol}^{-1}$ with those for the corresponding NP models. This observation corroborates the suitability of the employed NP models to represent bigger Pd NPs studied experimentally.

The prominent difference between NPs and single crystals becomes evident when $\mathrm{H}$ is introduced into subsurface region of Pd. For the subsurface-saturated NP it causes further strong reduction of the Gibbs activation energy by $24 \mathrm{~kJ} \mathrm{~mol}^{-1}$ (Table 1). Such barrier lowering should increase the reaction rate by four orders of magnitude compared to the surface-saturated NP without $\mathrm{H}^{\text {sub }}$. At the same time, the addition of $\mathrm{H}^{\text {sub }}$ atoms to surfacesaturated single crystal decreases the barrier by only $\sim 5 \mathrm{~kJ} \mathrm{~mol}^{-1}$ and accelerates the reaction 
tenfold. Hence, we conclude that dramatically accelerated hydrogenation on $\mathrm{Pd}$ can be achieved via the synergy of high $\mathrm{H}^{\text {sub }}$ content and catalyst nanostructuring. ${ }^{[17]}$

In order to further evaluate the contributions to the barrier lowering by various $\mathrm{H}^{a d}$ and $\mathrm{H}^{\text {sub }}$ atoms surrounding the reacting species, we considered two more models derived from the most reactive subsurface-saturated NP model $\mathrm{H}^{a d}{ }_{78} \mathrm{H}^{\text {sub }}{ }_{24} / \mathrm{Pd}(\mathrm{NP})$. First, the most distant $\mathrm{H}^{a d}$ and $\mathrm{H}^{\text {sub }}$ atoms were removed from the $\{111\}$ NP facet that accommodates ethyl reactant, giving $\mathrm{H}^{a d}{ }_{38} \mathrm{H}^{\text {sub }}{ }_{12} / \mathrm{Pd}(\mathrm{NP})$ model. Subsequent removal of $\mathrm{H}$ atoms most distant from the reaction site results in the model $\mathrm{H}^{a d}{ }_{23} \mathrm{H}^{\text {sub }}{ }_{3} / \mathrm{Pd}(\mathrm{NP})$ (see Figure $\mathrm{S} 3$ ). For the $\mathrm{H}^{a d}{ }_{38} \mathrm{H}^{\text {sub }}{ }_{12} / \mathrm{Pd}(\mathrm{NP})$ model, the Gibbs activation barrier of the hydrogenation is $9 \mathrm{~kJ} \mathrm{~mol}^{-1}$, close to that of the subsurface-saturated NP containing about twice as many $\mathrm{H}^{a d}$ and $\mathrm{H}^{\text {sub }}$ atoms. The model with only three $\mathrm{H}^{\text {sub }}$ atoms located below the reaction site, $\mathrm{H}^{a d}{ }_{23} \mathrm{H}^{\text {sub }}{ }_{3} / \mathrm{Pd}(\mathrm{NP})$, features a barrier height of $28 \mathrm{~kJ} \mathrm{~mol}^{-1}$, the same as on the surfacesaturated NP without any $\mathrm{H}^{\text {sub }}$ atoms. Thus, solely the $\mathrm{H}^{\text {sub }}$ atoms right beneath the hydrogenation sites on Pd NP are likely insufficient to notably lower the barrier. Rather, the effect of the overall concentration of $\mathrm{H}^{\text {sub }}$ on the barrier height appears to be gradual. Indeed, the Pd NPs with increasing number of $\mathrm{H}^{\text {sub }}$ atoms, $\mathrm{H}^{a d}{ }_{78} \mathrm{H}^{\text {sub }}{ }_{0} \rightarrow \mathrm{H}^{a d}{ }_{23} \mathrm{H}^{\text {sub }}{ }_{3} \rightarrow \mathrm{H}^{a d}{ }_{38} \mathrm{H}^{\text {sub }}{ }_{12} \rightarrow$ $\mathrm{H}^{a d}{ }_{78} \mathrm{H}^{\text {sub }}{ }_{24}$ exhibit decreasing activation barriers $29 \rightarrow 28 \rightarrow 9 \rightarrow 5 \mathrm{~kJ} \mathrm{~mol}^{-1}$. A similar, but much weaker effect could also be seen on Pd(111) models: the barrier drops from 31 to $26 \mathrm{~kJ}$ $\mathrm{mol}^{-1}$ while switching from surface-saturated to subsurface-saturated single-crystal model. Doubling the $\mathrm{H}^{\text {sub }}$ concentration in the subsurface-saturated single-crystal model (by filling the second subsurface layer) further decreases the Gibbs activation barrier from 26 to $18 \mathrm{~kJ}$ $\mathrm{mol}^{-1}$. In line with the experimental observations (Figure S1 and the second paragraph in SI), this finding suggests that Pd(111) single-crystal can be as active as Pd NPs in hydrogenation of alkyls, but only at rather high concentration of $\mathrm{H}^{\text {sub }}$, which may be difficult to maintain in steady state reaction regime.

What are the fundamental reasons for the enhanced hydrogenation activity of Pd NPs in the presence of $\mathrm{H}^{\text {sub }}$ species and why is the activation less efficient on the extended $\operatorname{Pd}(111)$ surface? To answer these questions, we analyze the energy contributions that determine the barrier heights. From the binding energy of ethyl $+\mathrm{H}$ considered as the initial state of the process, IS, $\mathrm{E}_{\mathrm{b}}{ }^{\mathrm{IS}}$ (Table 1), one notices that the increase in the $\mathrm{H}$ content gradually destabilizes the IS structures on NP and, to a lesser extent, on single-crystal models. The transition state (TS) destabilization caused by $\mathrm{H}^{\text {sub }}$ atoms is not so strong, as seen from its binding energy, $\mathrm{E}_{\mathrm{b}}{ }^{\mathrm{TS}}$ (Table 1). The different destabilization of the IS and TS structures by $\mathrm{H}^{\text {sub }}$ atoms deter- 
mines the activation energies, which are lowered by $24 \mathrm{~kJ} \mathrm{~mol}^{-1}$ on the NP and by $5 \mathrm{~kJ} \mathrm{~mol}^{-1}$ on the single crystal when changing from surface-saturated to subsurface-saturated model.

The data presented in Table 1 suggest that the binding energy of an attacking $\mathrm{H}^{a d}$ (without co-adsorbed ethyl) is a descriptor of the surface hydrogenation reactivity. The adsorption energies of the probe atom $\mathrm{H}, \mathrm{E}_{b}(\mathrm{H})$, correlate with the activation energies of ethyl hydrogenation (Figure 2): lowering of $\mathrm{E}_{b}(\mathrm{H})$ is accompanied by a decrease of the Gibbs activation barrier by almost the same amount. Thus, a destabilization of $\mathrm{H}^{\text {ad }}$ by $\mathrm{H}^{\text {sub }}$, consistent with experimental observations, ${ }^{[18]}$ appears to be the main reason for the activation of Pd catalysts by subsurface $\mathrm{H}$, which is particularly strong on Pd NPs.

Examining the electronic structure of $\mathrm{Pd}$ with varying number of $\mathrm{H}^{\text {ad }}$ and $\mathrm{H}^{\text {sub }}$ atoms is the key to understanding the origin of the weakened adsorption of $\mathrm{H}$ atoms and their enhanced reactivity. Two effects are manifested in densities of states (DOS) projected on $\mathrm{H} s$ and $\mathrm{Pd} d$ states of atoms forming three-fold hollow hydrogenation sites $\mathrm{H}^{a d} \mathrm{Pd}_{3}$ (Figures 3, S3, S4). First, a shift of the $\mathrm{Pd} 4 d$ states to lower energies with increasing $\mathrm{H}$ content notably reduces the number of states at the Fermi level. The magnitude of these H-induced DOS shifts, ca. 0.3 $\mathrm{eV}$, is comparable to differences between $d$-band centers of such distinct metals as $\mathrm{Cu}$ and $\mathrm{Pt},{ }^{[19]}$ explaining the dramatic change in catalytic properties of $\mathrm{Pd}$ upon saturation with $\mathrm{H}$. The second effect is related to the DOS of the subsurface-saturated NP model, for which the lowest hydrogenation activation energy is computed. The H s-projected DOS reveals a small feature just below the Fermi level corresponding to a partial occupation of the antibonding $\mathrm{H}^{a d}-\mathrm{Pd}_{3}$ states (see asterisks in Figure 3). The latter, in line with the reactivity analysis of different late transition metals with respect to $\mathrm{H}^{[20]}$ results in a notably weaker interaction between $\mathrm{H}^{a d}$ and $\mathrm{Pd}$. Both effects on DOS plots described above are significantly stronger for NPs than for single-crystal models. Filling of subsurface sites by $\mathrm{H}$ atoms in the subsurfacesaturated single crystal does not lead to any noticeable occupation of the antibonding $\mathrm{H}^{a d}-\mathrm{Pd}$ states, consistent with the substantial ethyl hydrogenation barrier of $26 \mathrm{~kJ} \mathrm{~mol}^{-1}$. Thus, high sensitivity of NPs to changes in electronic structure upon interaction with hydrogen is crucial for activation of $\mathrm{Pd}$ by $\mathrm{H}^{\text {sub }}$. This explains why both subsurface hydrogen and nanostructuring of Pd catalysts are necessary for the high observed steady state hydrogenation activity. Note that changes in geometric structure of $\mathrm{Pd}$ catalysts induced by $\mathrm{H}^{\text {sub }}$ cannot explain the increase in the hydrogenation activity (see SI).

Having analyzed the interplay between $\mathrm{H}^{\text {sub }}$ content and hydrogenation catalytic activity for Pd, we explored to what extent the trends identified for Pd are inherent to transition metals in general. To this end we investigated other catalytically relevant metals $-\mathrm{Pt}, \mathrm{Ni}$ and $\mathrm{Rh}-$ 
using the same models as for Pd and calculated binding energies of adsorbed hydrogen, $\mathrm{E}_{\mathrm{b}}(\mathrm{H})$, as a descriptor of the hydrogenating activity, and its dependence on the content of subsurface hydrogen. For one of the metals, Ni, we also calculated hydrogenation rates, Figure $1 b$, which are shown to be related to $E_{b}(H)$, as discussed above for Pd.

The results collected in Table 2 suggest that Pt behaves similarly to $\mathrm{Pd}-$ the binding energy of $\mathrm{H}^{\text {ad }}$ is decreased in magnitude from $-49 \mathrm{~kJ} \mathrm{~mol}^{-1}$ on the low-coverage Pt NP to -13 $\mathrm{kJ} \mathrm{mol}^{-1}$ on the subsurface-saturated NP. Again this sharp weakening of $\mathrm{H}^{a d}$ binding is related to changes in the electronic structure and partial occupation of antibonding H-Pt states (Figure S5). On the single-crystal $\mathrm{Pt}(111)$ surface the weakening of $\mathrm{H}^{\text {ad }}$ binding is much more modest, only to $-30 \mathrm{~kJ} \mathrm{~mol}^{-1}$ for the subsurface-saturated model.

In contrast, the binding nature of hydrogen to $\mathrm{Ni}$ and $\mathrm{Rh}$ appears to be remarkably different from that to $\mathrm{Pd}$ and $\mathrm{Pt}$ due to distinctively polar $\mathrm{H}-\mathrm{Ni}$ and $\mathrm{H}-\mathrm{Rh}$ bonds with significantly larger electron density accumulated on hydrogen and concomitantly increased positive charge on metal atoms (Table 2). Addition of $\mathrm{H}^{\text {sub }}$ to hydrogen-loaded $\mathrm{Ni}$ and $\mathrm{Rh}$ systems is predicted to lead to further electron depletion from the surface metal atoms and increase their electrostatic attraction to the adsorbed (noticeably negatively charged) $\mathrm{H}^{a d}$ atoms. Thus, in striking variance with $\mathrm{Pd}$ and $\mathrm{Pt}$, the presence of $\mathrm{H}^{\text {sub }}$ in Ni and $\mathrm{Rh}$ makes $\mathrm{H}^{\text {ad }}$ atoms more strongly bound to the metal. Keeping in mind our findings for Pd, one could expect that this stabilization results in decreased activity of $\mathrm{H}^{\text {ad }}$ in the presence of $\mathrm{H}^{\text {sub }}$. Indeed, we calculated (Table 1, Figure 1 b) that on Ni nanoparticles $\mathrm{H}^{\text {sub }}$ slows down ethyl hydrogenation by three orders of magnitude.

In summary, we determined two mechanisms by which subsurface $\mathrm{H}$ may affect the activity of transition metals, in particular, in hydrogenation reactions. On Pd and Pt subsurface $\mathrm{H}$ destabilizes adsorbed $\mathrm{H}$ via changing the electronic structure of metals, causing occupation of anti-bonding $\mathrm{H}^{a d}$-Pd or $\mathrm{H}^{a d}$-Pt electronic states. This effect is stronger on metal NPs than on single crystals and is sufficient to accelerate alkyl hydrogenation by several orders of magnitude on Pd NPs. Moreover, the hydrogenation rate is found to increase gradually with increasing $\mathrm{H}^{\text {sub }}$ content even at a distance from the reaction site. Thus, the structure of active sites alone (similar in NPs and single crystals) does not yet determine the reactivity. Our findings help to clarify a long-standing puzzle why both subsurface hydrogen and nanostructuring of Pd catalysts are necessary for the observed high steady-state olefin hydrogenation activity. Importantly, the outlined mechanism of $\mathrm{H}^{\text {ad }}$ activation is inherent to $\mathrm{H}-\mathrm{Pd}$ and $\mathrm{H}-\mathrm{Pt}$ interactions and, thus, should affect various hydrogenation (and dehydrogenation) reactions on these catalysts. In a very remarkable contrast, on $\mathrm{Ni}$ and $\mathrm{Rh}$ we have found another 
mechanism of interplay between adsorbed and subsurface $\mathrm{H}$, which leads to the stabilization of adsorbed $\mathrm{H}$. This behavior is due to the more polar character of $\mathrm{H}-\mathrm{Ni}$ and $\mathrm{H}-\mathrm{Rh}$ bonds, which leads to increased positive charge of surface metal atoms due to the presence of $\mathrm{H}^{\text {sub }}$ and consequently stronger electrostatic attraction of (negatively charged) $\mathrm{H}^{\text {ad }}$ to the surface. Notable deactivation of adsorbed $\mathrm{H}$ by subsurface $\mathrm{H}$ on Ni NPs is manifested by decreased reaction rates for ethyl hydrogenation. At the same time, desorption of surface $\mathrm{H}$ should be also hindered by subsurface $\mathrm{H}$ on $\mathrm{Ni}$ and $\mathrm{Rh}$, which may be beneficial for certain reactions. From practical point of view, the discussed mechanisms of destabilization or stabilization of adsorbed $\mathrm{H}$ by absorbed $\mathrm{H}$ may be used to tune catalytic activity of transition metals.

Keywords: density functional calculations · heterogeneous catalysis · hydrogenation nanoparticles $\cdot$ surface chemistry 
Table 1: Calculated data for ethyl hydrogenation catalyzed by Pd and Ni. Rate constant, activation and reaction Gibbs free energies at temperature $\mathrm{T}=298 \mathrm{~K}\left(k_{298}, \Delta \mathrm{G}^{\neq}{ }_{298}\right.$ and $\Delta \mathrm{G}_{298}$, respectively), binding energies $\left(\mathrm{E}_{\mathrm{b}}\right)$ of atom $\mathrm{H}^{\text {ad }}$ as well as those of initial state (IS) and transition state (TS) structures on various forms of the catalysts. ${ }^{[\mathrm{a}]}$

\begin{tabular}{|c|c|c|c|c|c|}
\hline \multirow[t]{2}{*}{ Model $^{[b]}$} & $k_{298^{[c]}}$ & $\Delta \mathrm{G}_{298}^{\neq} \quad \Delta \mathrm{G}_{298}$ & $\mathrm{E}_{\mathrm{b}}^{\mathrm{IS}}\left(\mathrm{C}_{2} \mathrm{H}_{5}+\mathrm{H}\right)$ & $\mathrm{E}_{\mathrm{b}}^{\mathrm{TS}}\left(\mathrm{C}_{2} \mathrm{H}_{5}+\mathrm{H}\right)$ & $\mathrm{E}_{\mathrm{b}}(\mathrm{H})$ \\
\hline & $\mathrm{s}^{-1}$ & $\mathrm{~kJ} \mathrm{~mol}^{-1} \mathrm{~kJ} \mathrm{~mol}^{-1}$ & $\mathrm{~kJ} \mathrm{~mol}^{-1}$ & $\mathrm{~kJ} \mathrm{~mol}^{-1}$ & $\mathrm{~kJ} \mathrm{~mol}^{-1}$ \\
\hline
\end{tabular}

Pd nanoparticle

$\begin{array}{lcccccr}\text { low-coverage }_{\text {surface-saturated }}{ }^{\text {[d] }} & 2 \times 10^{4} & 48 & -51 & -219 & -165 & -61 \\ & 5 \times 10^{7} & 29 & -100 & -178 & -133 & -51 \\ & \left(2 \times 10^{6}\right) & (37) & (-106) & & & \\ \text { subsurface-saturated }^{[\mathrm{d}]} & 8 \times 10^{11} & 5 & -142 & -134 & -119 & -15 \\ & \left(7 \times 10^{9}\right) & (17) & (-142) & & & \end{array}$

Pd single crystal

$\begin{array}{llllllr}\text { low-coverage } & 2 \times 10^{4} & 48 & -58 & -205 & -155 & -56 \\ \text { surface-saturated } & 2 \times 10^{7} & 31 & -103 & -174 & -133 & -43 \\ \text { subsurface-saturated } & 2 \times 10^{8} & 26 & -126 & -152 & -115 & -34\end{array}$

Ni nanoparticle

$\begin{array}{lllllll}\text { surface-saturated } & 1 \times 10^{7} & 33 & -105 & -176 & -132 & -66 \\ \begin{array}{l}\text { subsurface-saturated } \\ \text { Ni single crystal }\end{array} & 9 \times 10^{3} & 51 & -52 & -207 & -149 & -69 \\ \text { surface-saturated } & 1 \times 10^{10} & 16 & -137 & -147 & -122 & -51 \\ \text { subsurface-saturated } & 7 \times 10^{9} & 17 & -126 & -165 & -133 & -60\end{array}$

[a] $\mathrm{E}_{\mathrm{b}}$ is the binding energy to the metal substrate of either the co-adsorbed species $\mathrm{C}_{2} \mathrm{H}_{5}+\mathrm{H}$ (with respect to the energy of free $\mathrm{C}_{2} \mathrm{H}_{5}+1 / 2 \mathrm{H}_{2}$ ) or the atom $\mathrm{H}^{a d}$ involved in the hydrogenation (calculated without co-adsorbed ethyl, with respect to the energy of $1 / 2 \mathrm{H}_{2}$ ).

[b] See Figure 1.

[c] $k_{\mathrm{T}}=\left(\mathrm{k}_{\mathrm{B}} \mathrm{T} / \mathrm{h}\right) \times \exp \left(-\Delta \mathrm{G}^{\neq}{ }_{\mathrm{T}} / \mathrm{RT}\right)$, where $\mathrm{k}_{\mathrm{B}}, \mathrm{h}$ and $\mathrm{R}$ are Boltzmann, Planck and ideal gas constants, respectively.

[d] In parentheses, the data for butyl hydrogenation are shown. 
Table 2: Results for nanoparticle and (111) single-crystal models of transition metals interacting with a different number of hydrogen atoms. Binding energies of adsorbed hydrogen atoms, $\mathrm{E}_{b}(\mathrm{H})$, and calculated Bader charges, $\mathrm{q}$, of selected atoms.

\begin{tabular}{|c|c|c|c|c|c|c|c|c|c|c|c|c|}
\hline \multirow[t]{2}{*}{$\operatorname{Model}^{[\mathrm{a}]}$} & \multicolumn{4}{|c|}{$\mathrm{E}_{\mathrm{b}}(\mathrm{H}),{ }^{[\mathrm{b}]} \mathrm{kJ} \mathrm{mol}^{-1}$} & \multicolumn{4}{|c|}{$\mathrm{q}(\mathrm{H}),{ }^{[\mathrm{c}]}|\mathrm{e}|$} & \multicolumn{4}{|c|}{$\mathrm{q}(\mathrm{M}),{ }^{[\mathrm{d}]}|\mathrm{e}|$} \\
\hline & $\mathrm{Ni}$ & $\mathrm{Rh}$ & $\mathrm{Pd}$ & $\mathrm{Pt}$ & $\mathrm{Ni}$ & $\mathrm{Rh}$ & $\mathrm{Pd}$ & $\mathrm{Pt}$ & $\mathrm{Ni}$ & $\mathrm{Rh}$ & $\mathrm{Pd}$ & $\mathrm{Pt}$ \\
\hline \multicolumn{13}{|l|}{ Nanoparticle } \\
\hline low-coverage & -63 & -49 & -61 & -49 & -0.27 & -0.21 & -0.11 & -0.04 & 0.10 & 0.07 & 0.03 & 0.02 \\
\hline surface-saturated & -66 & -37 & -51 & -47 & -0.22 & -0.16 & -0.09 & -0.02 & 0.17 & 0.11 & 0.08 & 0.01 \\
\hline subsurface-saturated & -69 & -66 & -15 & -13 & $\begin{array}{l}-0.28 \\
(-0.27)\end{array}$ & $\begin{array}{l}-0.20 \\
(-0.15)\end{array}$ & $\begin{array}{l}-0.11 \\
(-0.08)\end{array}$ & $\begin{array}{l}-0.04 \\
(0.00)\end{array}$ & 0.29 & 0.19 & 0.11 & 0.05 \\
\hline \multicolumn{13}{|l|}{ Single crystal } \\
\hline low-coverage & -54 & -56 & -56 & -47 & -0.28 & -0.22 & -0.13 & -0.08 & 0.07 & 0.03 & 0.03 & -0.02 \\
\hline surface-saturated & -51 & -47 & -43 & -39 & -0.25 & -0.20 & -0.12 & -0.05 & 0.19 & 0.13 & 0.09 & 0.03 \\
\hline subsurface-saturated & -60 & -52 & -34 & -30 & $\begin{array}{l}-0.27 \\
(-0.29)\end{array}$ & $\begin{array}{l}-0.20 \\
(-0.17)\end{array}$ & $\begin{array}{l}-0.13 \\
(-0.11)\end{array}$ & $\begin{array}{l}-0.06 \\
(-0.01)\end{array}$ & 0.27 & 0.15 & 0.12 & 0.01 \\
\hline
\end{tabular}

[a] See models depicted in Figure 1.

[b] $\mathrm{E}_{\mathrm{b}}(\mathrm{H})$ is the binding (adsorption) energy of the $\mathrm{H}^{\text {ad }}$ atom involved in the hydrogenation (calculated without co-adsorbed ethyl species) vs. free $1 / 2 \mathrm{H}_{2}$.

[c] Average charges of all adsorbed atoms $\mathrm{H}^{a d}$, or, in parentheses, of all subsurface atoms $\mathrm{H}^{\text {sub }}$

[d] Average charges of the three metal atoms $M$, to which the attacking atom $\mathrm{H}^{\text {ad }}$ is coordinated. 

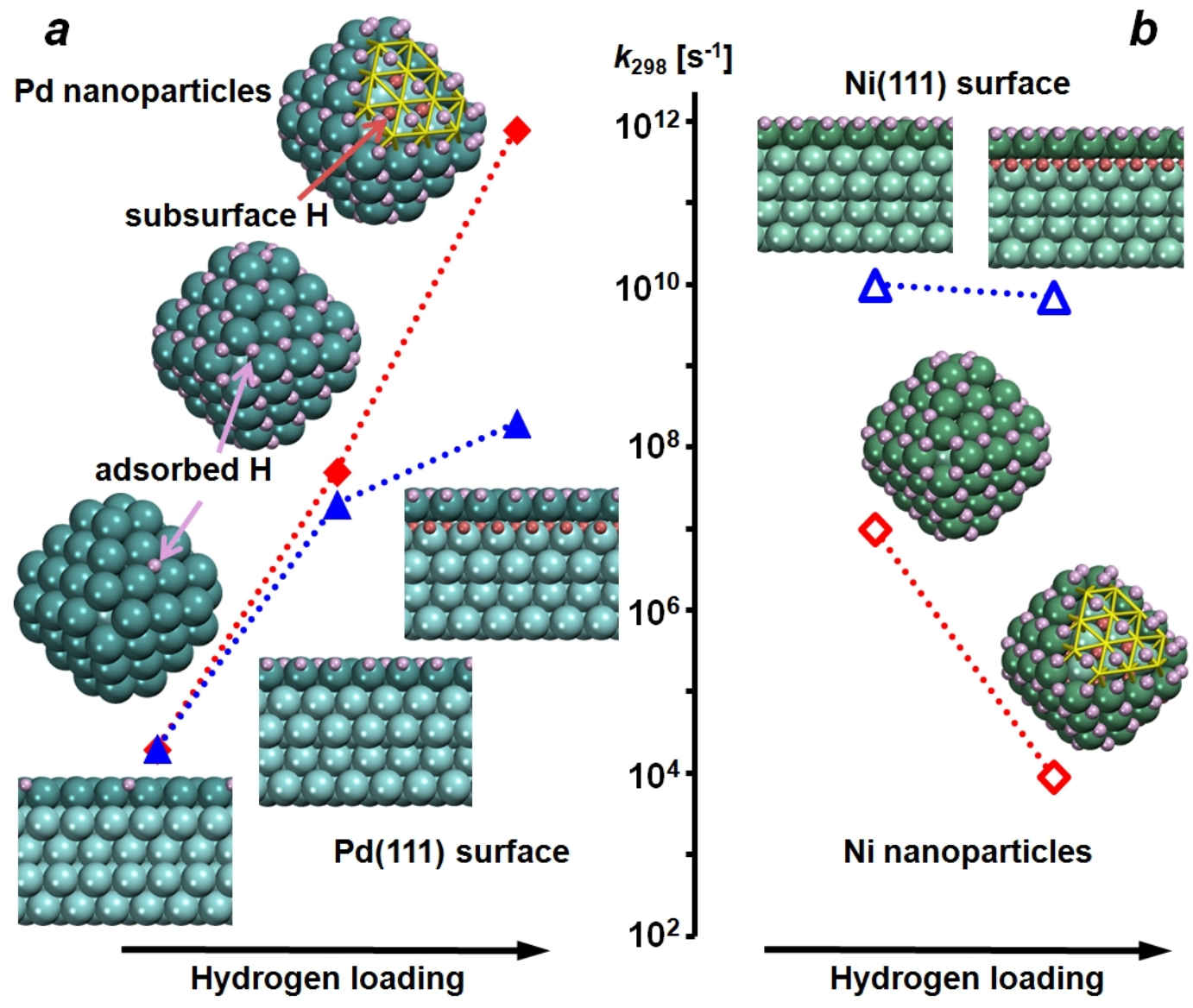

Figure 1: Calculated rate constant $k_{298}$ of ethyl hydrogenation on $\mathrm{Pd}(a)$ and $\mathrm{Ni}(b)$ at $298 \mathrm{~K}$ as a function of hydrogen loading and nanostructuring of the catalyst. Data for metal nanoparticles (red diamonds) and (111) single-crystals (blue triangles) are shown together with the sketches of the models. 


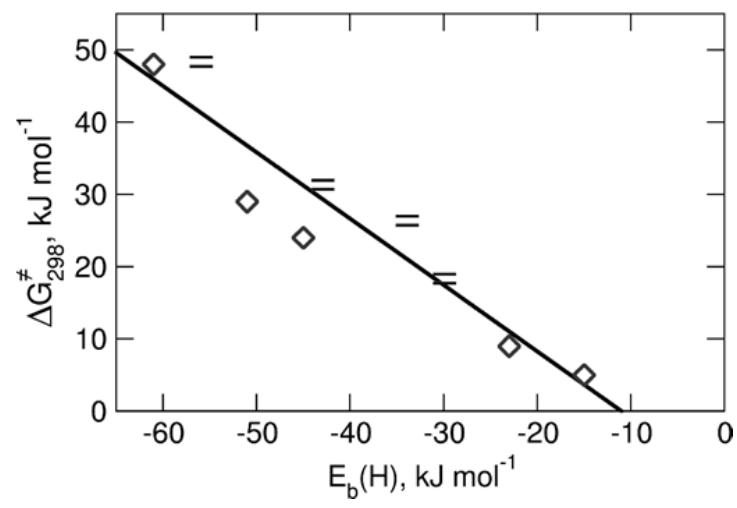

Figure 2: Correlation of activation barriers with adsorption energies of hydrogen. Activation Gibbs free energies of ethyl hydrogenation, $\Delta \mathrm{G}^{\neq}{ }_{298}$, as a function of $\mathrm{H}$ binding energies in IS, $\mathrm{E}_{\mathrm{b}}(\mathrm{H})$, calculated on Pd NP $(\diamond)$ and Pd(111) single crystal $(=)$ models.
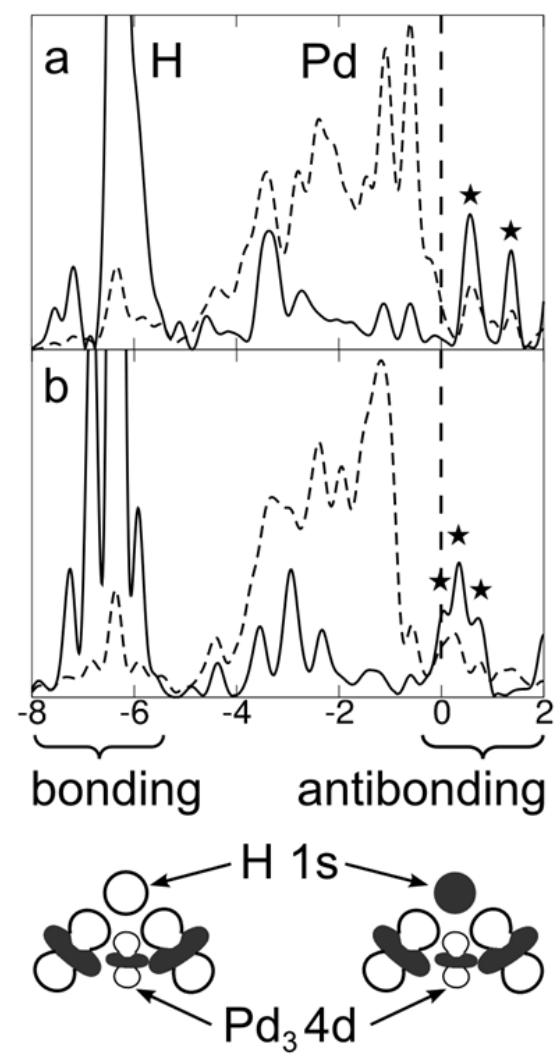

Figure 3: Dependence of the electronic structure of nanoparticulate $\mathrm{Pd}-\mathrm{H}$ systems on the hydrogen content: $a-\mathrm{Pd}_{79} \mathrm{NP}$ saturated with adsorbed hydrogen $\mathrm{H}^{a d}, b-\mathrm{Pd}_{79} \mathrm{NP}$ saturated with both adsorbed $\mathrm{H}^{a d}$ and subsurface $\mathrm{H}^{\text {sub }}$ hydrogen (see Figure 1a). The density of states (DOS) projected on: solid line $-s$ states of the reacting $\mathrm{H}^{\text {ad }}$ atom $(\times 50)$; dashed line $-d$ states of the atoms forming the hollow site $\mathrm{Pd}_{3}$, where the atom $\mathrm{H}^{\text {ad }}$ is located. DOS is given in arbitrary units, with respect to the Fermi energy $\varepsilon_{\mathrm{F}}=0 \mathrm{eV}$. The $\mathrm{H}-\mathrm{Pd}_{3}$ antibonding states (marked by asterisks) approach the Fermi level with increasing $\mathrm{H}$ content, resulting in their partial occupation in subsurface-saturated NP (panel $b$ ). 


\section{References}

[1] Handbook of Heterogeneous Catalysis (Eds.: G. Ertl, H. Knözinger, J. Weitkamp), Wiley-VCH, Weinheim, 1997.

[2] D. Teschner, J. Borsodi, A. Wootsch, Z. Révay, M. Hävecker, A. Knop-Gericke, S. D. Jackson, R. Schlögl, Science 2008, 320, 86-89.

[3] a) A. D. Johnson, S. P. Daley, A. L. Utz, S. T. Ceyer, Science 1992, 257, 223-225; b)

G. Henkelman, A. Arnaldsson, H. Jónsson, J. Chem. Phys. 2006, 124, 044706.

[4] S. T. Ceyer, Acc. Chem. Res. 2001, 34, 737-744.

[5] M. Wilde, K. Fukutani, W. Ludwig, B. Brandt, J.-H. Fischer, S. Schauermann, H.-J. Freund, Angew. Chem. Int. Ed. 2008, 47, 9289-9293; Angew. Chem. 2008, 120, 94309434.

[6] A. M. Doyle, S. K. Shaikhutdinov, S. D. Jackson, H.-J. Freund, Angew. Chem. Int. Ed. 2003, 42, 5240-5243; Angew. Chem. 2003, 115, 5398-5401.

[7] a) W. Ludwig, A. Savara, K.-H. Dostert, S. Schauermann, J. Catal. 2011, 284, 148156; b) W. Ludwig, A. Savara, S. Schauermann, H.-J. Freund, ChemPhysChem 2010, 11, 2319-2322.

[8] M. Armbrüster, M. Behrens, F. Cinquini, K. Föttinger, Y. Grin, A. Haghofer, B. Klötzer, A. Knop-Gericke, H. Lorenz, A. Ota, S. Penner, J. Prinz, C. Rameshan, Z. Révay, D. Rosenthal, G. Rupprechter, P. Sautet, R. Schlögl, L. Shao, L. Szentmiklósi, D. Teschner, D. Torres, R. Wagner, R. Widmer, G. Wowsnick, ChemCatChem 2012, 4, 1048-1063.

[9] a) M. Yamauchi, H. Kobayashi, H. Kitagawa, ChemPhysChem 2009, 10, 2566-2576; b) H. Kobayashi, H. Morita, M. Yamauchi, R. Ikeda, H. Kitagawa, Y. Kubota, K. Kato, M. Takata, J. Am. Chem. Soc. 2011, 133, 11034-11037.

[10] a) S. M. Kozlov, H. A. Aleksandrov, J. Goniakowski, K. M. Neyman, J. Chem. Phys. 2013, 139, 084701; b) S. M. Kozlov, H. A. Aleksandrov, K. M. Neyman, J. Phys. Chem. C 2014, 118, 15242-15250.

[11] I. V. Yudanov, R. Sahnoun, K. M. Neyman, N. Rösch, J. Chem. Phys. 2002, 117, 98879896.

[12] H. A. Aleksandrov, F. Viñes, W. Ludwig, S. Schauermann, K. M. Neyman, Chem. Eur. J. 2013, 19, 1335-1345.

[13] P. Ferrin, S. Kandoi, A. U. Nielekar, M. Mavrikakis, Surf. Sci. 2012, 606, 679-689.

[14] K. M. Neyman, S. Schauermann, Angew. Chem. Int. Ed. 2010, 49, 4743-4746; Angew. Chem. 2010, 122, 4851-4854.

[15] a) J. Greeley, M. Mavrikakis, Surf. Sci. 2003, 540, 215-229; b) J. Greeley, W. P. Krekelberg, M. Mavrikakis, Angew. Chem. Int. Ed. 2004, 43, 4296 -4300; Angew. Chem. 2004, 116, $4396-4400$.

[16] Leaving vacant only surface sites required for modelling adsorption and hydrogenation of olefin reactant.

[17] Not only the activation barriers can be affected by co-adsorbed species, such as $\mathrm{H}^{\text {sub }}$ or hydrocarbons. Also, the binding energies of the intermediates can be influenced, which might modify the concentrations and the relative distribution of all surface species in a complex way. Description of this complicated interplay using extensive electronic structure and kinetic Monte-Carlo calculations is beyond the scope of this communication.

[18] E. C. H. Sykes, L. C. Fernández-Torres, S. U. Nanayakkara, B. A. Mantooth, R. M. Nevin, P. S. Weiss, PNAS 2005, 102, 17907-17911.

[19] A. Ruban, B. Hammer, P. Stoltze, H. L. Skriver, J. K. Nørskov, J. Mol. Catal. A 1997, 115, 421-429.

[20] B. Hammer, J. K. Nørskov, Nature 1995, 376, 238-240. 